\title{
Description of two new species of the genus Chlorogomphus Selys, 1854 (Odonata: Chlorogomphidae) and a new record of Chlorogomphus gracilis Wilson \& Reels, 2001 from the Central Highlands of Vietnam
}

\author{
Quoc Toan PHAN ${ }^{\circledR 1, *} \&$ Haruki KARUBE ${ }^{2}$ \\ ${ }^{1}$ The Center for Entomology \& Parasitology Research, College of Medicine and Pharmacy, \\ Duy Tan University, Da Nang 550000, Vietnam. \\ ${ }^{2}$ Kanagawa Prefectural Museum of Natural History, Iryuda 499, \\ Odawara, Kanagawa 250-0031, Japan. \\ *Corresponding author: pqtoan84@gmail.com; phanquoctoan1@duytan.edu.vn \\ 2Email: paruki@nh.kanagawa-museum.jp \\ ${ }^{1}$ urn:lsid:zoobank.org:author:9DBB241C-A070-45DF-A111-B7BDDB56EEEE \\ ${ }^{2}$ urn:1sid:zoobank.org:author:71130445-C130-4CC4-B161-CE2DEEF1DFB6
}

\begin{abstract}
Two new species of the genus Chlorogomphus are described based on both sexes collected from the Central Highlands of Vietnam. These species are $C$. hoaian sp. nov. (holotype male from Kon Ka Kinh National Park, $14.3672^{\circ} \mathrm{N}, 108.5368^{\circ} \mathrm{E}$, alt. $1000 \mathrm{~m}$ ) and C. vani sp. nov. (holotype male from Chu Yang Sin National Park, $12.4780^{\circ} \mathrm{N}, 108.4617^{\circ} \mathrm{E}$, alt. $749 \mathrm{~m}$ ). Furthermore, C. gracilis Wilson \& Reels, 2001 is recorded from Vietnam for the first time, with notes on its morphology and detailed illustrations of male and female structures.
\end{abstract}

Keywords. Odonata, Chlorogomphus, new species, Vietnam.

Phan Q.T. \& Karube H. 2022. Description of two new species of the genus Chlorogomphus Selys, 1854 (Odonata: Chlorogomphidae) and a new record of Chlorogomphus gracilis Wilson \& Reels, 2001 from the Central Highlands of Vietnam. European Journal of Taxonomy 794: 91-110. https://doi.org/10.5852/ejt.2022.794.1657

\section{Introduction}

The genus Chlorogomphus Selys, 1854 comprises 45 species (Paulson et al. 2021), with several unidentified species recorded from China by Zhang (2019). In Vietnam, Martin (1910) described C. auratus, and Martin \& Asahina (1969) described C. vietnamensis Asahina from northern regions, all based on female specimens. Males were subsequently described by Karube (1995, 2013). Karube (1995) described four new species, namely C. albomarginatus, C. nakamurai, C. sachiyoae and C. takakuwai, and recorded C. nasutus Needham, 1930 from Vietnam. Asahina $(1995,1998)$ also reported C. auratus, C. nasutus, C. takakuwai, C. nakamurai and C. miyashitai Karube, 1995, all from northern Vietnam. Recently, several new species have been discovered, and new records have been documented from different Vietnamese locations: C. hiten (Sasamoto, Yokoi \& Teramoto, 2011), C. papilio Ris, 1927 and C. piaoacensis Karube, 2013 were discovered in the North; C. canhvang Kompier \& Karube, 2018 and 
C. danhkyi Phan, Karube, Hung \& Anh, 2021 were found in the Central-North; and C. aritai Karube, 2013 and C. caloptera Karube, 2013 were collected from the Central Highlands (Karube 2013, 2015; Kompier 2014; Kompier \& Karube 2018; Phan et al. 2021).

Here, we describe two additional species, Chlorogomphus hoaian sp. nov. from Kon Ka Kinh National Park, Gia Lai Province, and C. vani sp. nov. from Chu Yang Sin National Park, Dak Lak Province, and provide a new record of $C$. gracilis Wilson \& Reels, 2001 from Ngoc Linh Nature Reserve, Kon Tum Province. All these locations are located in the Central Highlands of Vietnam. With these two new species and one new record, the total number of species of Chlorogomphus in Vietnam reaches 18. We also provide detailed color photographs and illustrations of the male and female structures of C. gracilis and discuss its morphological variations.

The systematics of the genus Chlorogomphus in Vietnam has been a controversial issue. Karube (2013) allocated 10 Vietnamese species within six subgenera as follows: Neorogomphus Carle, 1995 (type species: C. fraseri St. Quentin, 1936; including C. auratus and C. caloptera), Nubatamachlorus Karube, 2013 (type species: C. nakamurai; including C. aritai), Vietnamchlorus Karube, 2013 (including only the type species, C. albomarginatus), Orogomphus Selys, 1878 (type species: C. splendidus (Selys, 1878); including C. piaoacensis), Sinorogomphus Carle, 1995 (type species: C. nasutus; including C. tunti Needham, 1930, C. sachiyoae and C. vietnamensis) and Petaliorogomphus Karube, 2013 (type species: C. takakuwai). Phan et al. (2021) followed this systematic arrangement and placed a new species, $C$. danhkyi, in the subgenus Orogomphus without explanation. Karube \& Phan (2016) recorded C. papilio and Kompier \& Karube (2018) described C. canhvang from Vietnam, without assigning these species to any subgenus. According to Karube (2013), the subfamilial taxonomy within Chlorogomphidae has long been debated, including the allocation of many doubtful species described based only on female specimens. These issues require a complete revision study based on morphology and molecular phylogeny (Karube 2013). Based on our knowledge, the current systematics within this family is a complicated problem, and the supporting DNA evidence is still lacking. Therefore, it would be imprudent to assign the two new species to any subgenus, as Karube (2013) suggested.

\section{Material and methods}

Specimens were collected and kept alive for 24 hours to remove their intestinal contents. They were subsequently steeped in acetone for 12-18 hours and dried for 2-4 hours. Each specimen is preserved in a square paper envelope accompanied by locality data. Specimens were examined and photographed using a Zeiss Stemi 508 microscope with an Axiocam Erc 5s camera. Habitus photos of type specimens were taken with a Nikon D850 digital camera and a Nikon AFS DX Micro Nikkor with an $85 \mathrm{~mm} \mathrm{f} / 3.5 \mathrm{G}$ ED VR lens. Illustrations were rendered using Photoshop ver. 7.0 software.

We generally followed the terminology in Kompier \& Karube (2018). The only exception is the term "valvula valvae", referring to the structure on the ventral $8^{\text {th }}$ abdominal segment; this term was described by Karube (2013).

The material described here has been deposited at the Zoological Collection of Duy Tan University, Da Nang, Vietnam (ZCDTU) and at Kanagawa Prefectural Museum of Natural History, Odawara, Japan (KPMNH).

We also provide photographs of specimens of other species of Chlorogomphus, namely:

Chlorogomphus fraseri St. Quentin, 1936: 1 đે, India, Meghalaya, Shilling, Khasi Hills, unknown date and collector (KPMNH Khasi01-ODO). 
Chlorogomphus aritai Karube, 2013: 1 ภ, Vietnam, Da Nang City, Ba Na Nui Chua Nature Reserve, $15.9966^{\circ} \mathrm{N}, 108.0067^{\circ} \mathrm{E}$, alt. $1200 \mathrm{~m}, 19$ Jun. 2017, Q.T. Phan leg. (ZCDTU 2017061901-ODO); 1 q, Vietnam, Da Nang City, Hoa Vang District, Hoa Trung Commune, $16.0947^{\circ} \mathrm{N}, 108.0349^{\circ}$ E, alt. $234 \mathrm{~m}$, 19 Jun. 2021, Q.T. Phan leg. (ZCDTU 2021061901).

Chlorogomphus auratus Martin, 1910: 1 , , Vietnam, Lang Son Province, Loc Binh District, Mau Son Mount, $21.8454^{\circ} \mathrm{N}, 106.9220^{\circ}$ E, alt. 876 m, 9 Jun. 2020, Q.T. Phan leg. (ZCDTU 2020060905-ODO).

Chlorogomphus caloptera Karube, 2013: 1 , Vietnam, Lam Dong Province, Bao Loc City, Doi Cao, $11.6430^{\circ}$ N, $107.6889^{\circ}$ E, alt. 746 m, 22 Apr. 2016, Q.T. Phan leg. (ZCDTU 2016042201-ODO).
Abbreviations
$\mathrm{Ax}=$ antenodal crossveins
$\mathrm{FW} \quad=$ fore wing
$\mathrm{Hw}=$ hind wing
$\mathrm{Pt}=$ pterostigma
Px $=$ postnodal crossveins
S1-10 = abdominal segments 1 to 10

\title{
Results
}

\author{
Class Insecta Linnaeus, 1758 \\ Order Odonata Fabricius, 1793 \\ Suborder Anisoptera Selys, 1854 \\ Family Chlorogomphidae Needham, 1903 \\ Genus Chlorogomphus Selys, 1854 \\ Chlorogomphus hoaian sp. nov. \\ urn:1sid:zoobank.org:act:52E0216D-18F2-4C0A-A7E0-523778EBDFA2
}

Figs 1-14, 21, 24-25, 61

\section{Diagnosis}

In lateral view, Chlorogomphus hoaian sp. nov. shows short, robust cerci and an epiproct which are generally similar to those of seven other species: C. aritai, C. arooni Asahina, 1981, C. caloptera, C. daviesi Karube, 2001, C. fraseri, C. nakamurai and C. yokoii Karube, 1995. However, C. hoaian sp. nov. is different from these seven species in major characteristics (alternative characters for the seven other species in parentheses): the cerci (Figs 12-13) are subequal in length to the epiproct (half as long except in C. caloptera); the dorsoposterior margin of S10 is broadly convex (narrowly convex); the length of the cerci is half that of the epiproct and S10 extends apically (except in C. caloptera, C. arooni (Asahina 1981: figs 7-8), C. caloptera (Karube 2013: fig. 6g), C. daviesi (Karube 2001: figs 5-6) and C. yokoii (Karube 1995: figs 15-16); the cerci are acute apically (Fig. 12) (blunt apically in C. nakamurai; see Karube 1995: figs 36-37).

Chlorogomphus hoaian sp. nov. is most similar to $C$. fraseri and $C$. aritai by the length of the cerci relative to that of the epiproct. Compared to Chlorogomphus fraseri, the cerci of $C$. hoaian sp. nov. are triangular in lateral view (Fig. 12), widely separated basally in dorsal view and lack a laterobasal spine (Fig. 13); the epiproct in lateral view is triangular, expanded posteroventrally and armed with a pair of erect inner dorsal projections, separated from each other by a distance greater than the basal width of each projection (Fig. 13) and directed laterally near the apex (Figs 12-14). In C. fraseri, the cerci are broad basally in dorsal view (Fig. 16), abruptly narrowed thereafter, with the apex strongly 
bent ventrally in lateral view (Fig. 15), abruptly swollen basally medially and laterally in dorsal view (Fig. 16); the bifurcate epiproct in lateral view extends slightly beyond the level of the tip of the cerci; in dorsal view the apex of the epiproct is armed with small teeth dorsally, laterally and apically, with a pair of subbasal, bidentate inner dorsal projections (Figs 15-17). Although structurally similar, the known ranges of the two species are separated by about $2200 \mathrm{~km}$ (Fig. 63).

Compared to those of Chlorogomphus aritai, the male cerci of $C$. hoaian sp. nov. are armed with a pair of large inner dorsal projections, easily visible in lateral view (Fig. 12), dorsally smoothly concave basally and then slightly convex distally, the apex not pointed in dorsal view and directed posterolaterally (Fig. 13), whereas in C. aritai, the inner dorsal projections are short, not visible in lateral view (Fig. 18) and the cercus is armed laterobasally with a strong acute spine, its apex acute and directed posteriorly (Fig. 19). The epiproct of $C$. hoaian sp. nov. is widely divaricate, broadly U-shaped (Fig. 14), but in $C$. aritai, the branches of the epiproct are strongly curved with tips almost touching, forming an incomplete circle (Fig. 20).

The wing pattern in females of Chlorogomphus hoaian sp. nov. is similar to that of C. caloptera (Figs 21, 23), but the brownish markings on both wings are less extensive than those in C. aritai (Fig. 22). Moreover, the vertex in the female of $C$. hoaian sp. nov. is armed posteriorly with a well-developed club-like process (Fig. 25), somewhat similar to C. aritai (Karube 2013: fig. 8b 2 ), while the posterior margin of the vertex is deeply incised in C. caloptera (Karube 2013: fig. 6b). No specimens of $C$. fraseri females have been reported.

\section{Etymology}

'Hoaian', named after Mrs Van Cong Hoai An (born 1992) of Da Nang City, Vietnam, the wife of the first author, a noun in apposition.

\section{Material examined}

\section{Holotype}

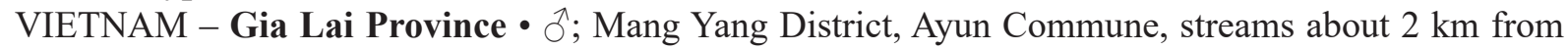
Kon Ka Kinh National Park Headquarters; $14.3672^{\circ}$ N, 108.5368 E; alt. 1000 m; 20 Apr. 2019; Q.T. Phan leg.; ZCDTU 2019042001-ODO.

Paratypes $(13 \hat{\jmath} \hat{\partial}, 5$ $\phi$ $)$

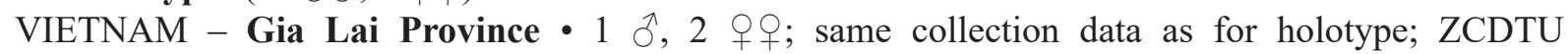

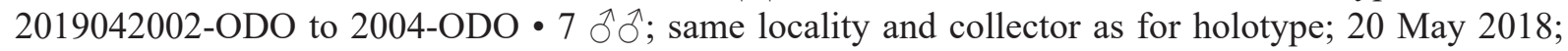

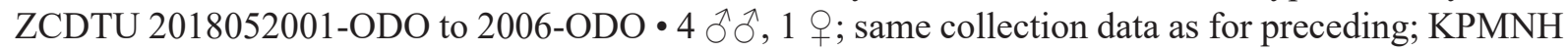
2018052007 to 2011 - 1 ; Ka Bang District, Dak Roong Commune, Dak Trum village; $14.6845^{\circ} \mathrm{N}$, 108.7667 E; alt. 923 m; 24 May 2018; Q.T. Phan leg.; ZCDTU 2018052401-ODO. - Kon Tum Province - 1 ग, 1 O ; Dak Glei District, Dak Man Commune, $2 \mathrm{~km}$ from Headquarters of Ngoc Linh Nature Reserve; $15.1471^{\circ}$ N, $107.7526^{\circ}$ E, alt. 1008 m; 7 Jun. 2019; Q.T. Phan leg.; ZCDTU 2019060701-ODO to 0702-ODO.

\section{Description}

Male (Figs 1, 3-4, 7-9, 12-14, 24)

MEASUREMENTS. Hw $51 \mathrm{~mm}$ long, abdomen (including anal appendages) $55 \mathrm{~mm}$ long.

HEAD. Labrum shines black with a small U-shaped yellow marking medially. Anteclypeus black, with lower and upper margins yellow. Postclypeus yellow with lower margin black. Antefrons entirely black. Postfrons black with a large transverse yellow stripe. Distance between eyes $0.7 \mathrm{~mm}$. Antennae 


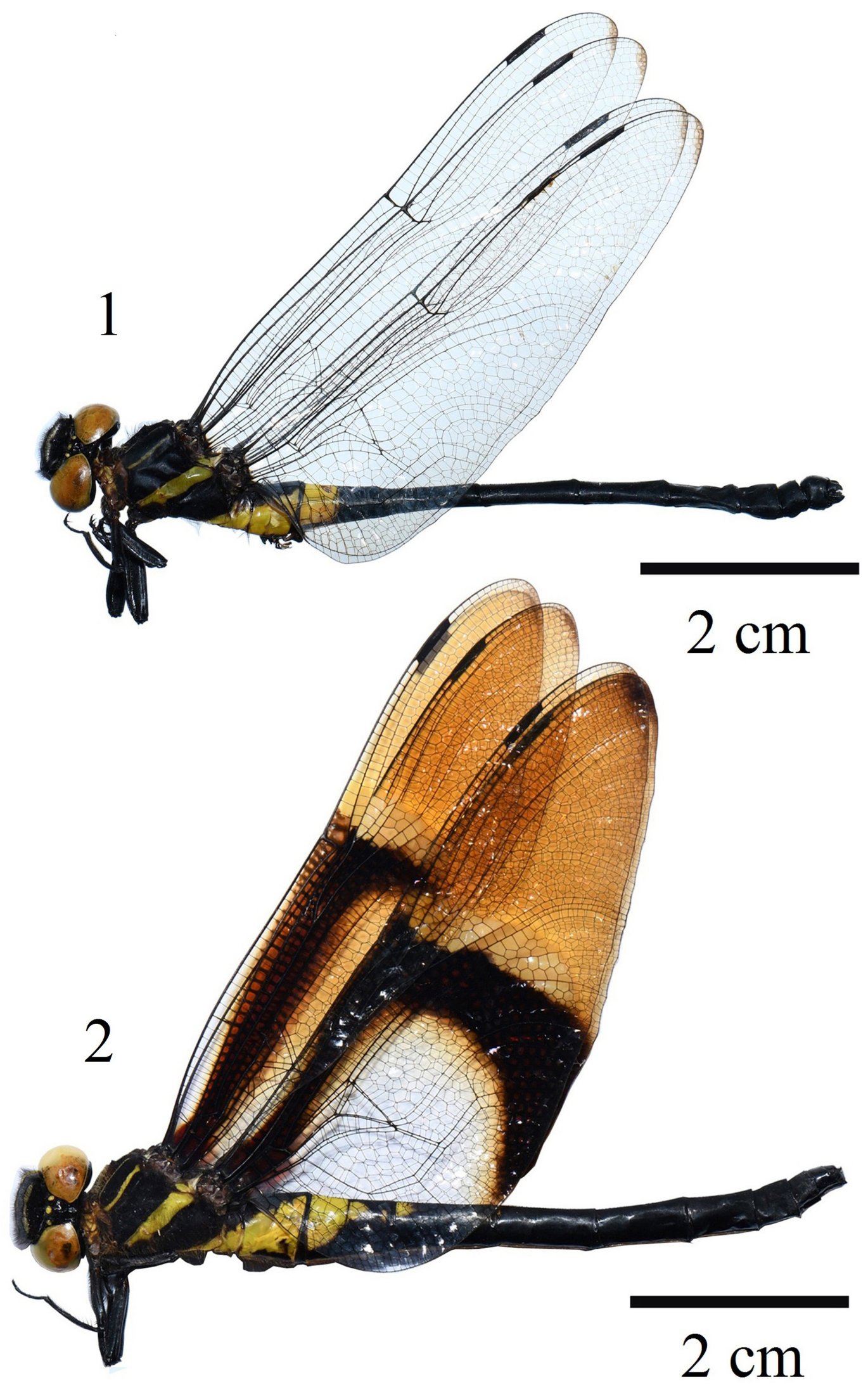

Figs 1-2. Habitus of Chlorogomphus hoaian sp. nov. 1. Holotype, §̊ (ZCDTU 2019042001-ODO). 2. Paratype, $q$ (ZCDTU 2019042003-ODO). 
black with pale second segment of anterior part (Figs 3-4). Vertex subtriangular with a longitudinal prominence dorsally (Fig. 24). Occiput black, triangular, armed with long setae posteriorly.

ThORAX. Prothorax black with anterior margin of anterior pronotal lobe yellow. Synthorax black with a dorsal thin whitish stripe and a narrow antehumeral stripe along lower margin of mesepisternum. Mesepimeron entirely black with a broad, almost parallel-sided yellow stripe covering spiracle; metepimeron black, lined with a narrow yellow stripe on ventral margin. Legs black (Fig. 1).

Wings. Wings hyaline, brownish at tip. Ax/Px ratio 28/16 in Fw and 19/17 in Hw. All wings with a median space with 2 crossveins. Anal triangle in Hw with 3 cells. Triangles of all wings with 3 cells, with basal side longer than costal side. In all wings, cubital space with 8-9 crossveins. Anal loop with 16 cells. Pt black, 4.5-5 mm long in all wings, covering 3-3.5 underlying cells (Fig. 1).

ABDOMEN. S1 with a broad oblique stripe, terminating dorsally at end of S2; basal half of S3 yellow and S4-10 black (Fig. 1).

SeCONDARY GENITALIA. Anterior lamina in lateral view robust, broad basally, tapering towards apex, strongly petiolate posteriorly. Posterior hamule slender, slightly longer than anterior lamina, curved anteriad (Fig. 7).
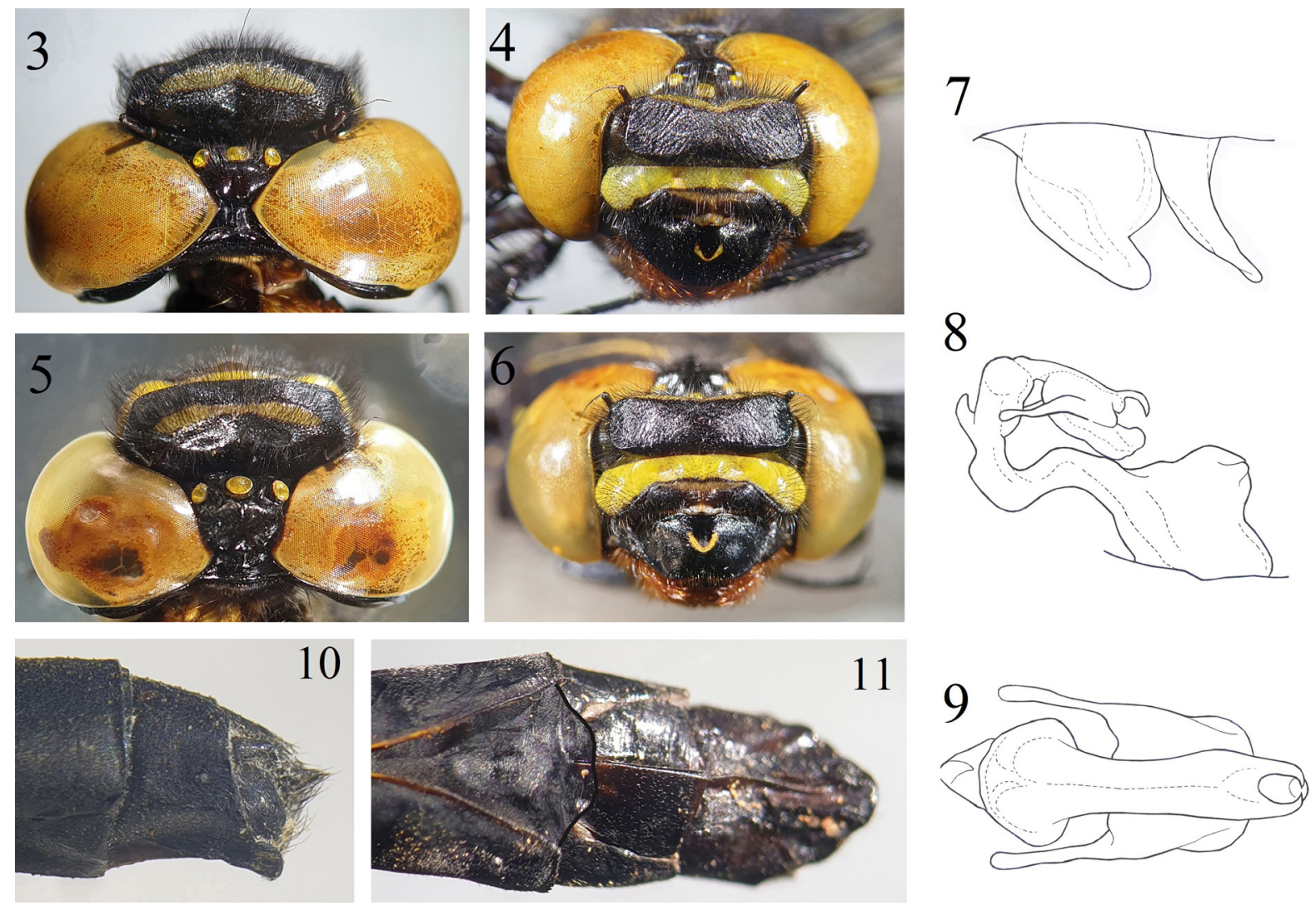

Figs 3-11. Features of Chlorogomphus hoaian sp. nov., holotype, $ð(3-4,7-9)$ (ZCDTU 2019042001ODO) and paratype, ${ }^{2}(5-6,10-11)$ (ZCDTU 2019042003-ODO). 3-4. Head in dorsal and frontal views. 5-6. Head in dorsal and frontal views. 7. Accessory genitalia. 8. Vesica spermalis in lateral view. 9. Terminal segment of vesica spermalis in ventral view. 10-11. Abdominal tip in lateral and ventral views. Images not to scale. 
VeSICA SPERMALIs. With typical shape in genus. Terminal segment with a well-developed lateral keel with a pair of long, curvilinear directed projections at posterior corners. Apical lobes of ventral plate short, hook-like in lateral view. Dorsal part of terminal segment subequal to ventral part. Second segment broad, with a stout spine (Figs 8-9).

ANAL APPENDAGES. Black. Cercus in lateral view shorter than S10, broad basally, tapering toward apex, with tip curved posteroventrally (Fig. 12) and a small lateral projection with long setae apically on distal third. In dorsal view, cerci widely separated at tip, concave subapically (Fig. 13). Epiproct slightly longer than cerci, bearing a pair of large inner dorsal projections, broadly based and tridentate. In lateral view, epiproct expanded apically, dorsal margin serrated apically, inner dorsal projections clearly visible (Fig. 12). In dorsal view, epiproct deeply incised, U-shaped, branches widely separated (Fig. 14). In ventral view, epiproct broad at base, rounded apically (Fig. 14).

Female (Figs 2, 5-6, 10-11, 21, 25)

MeASurements. Hw $60 \mathrm{~mm}$ long, abdomen (including appendages) $56 \mathrm{~mm}$ long.
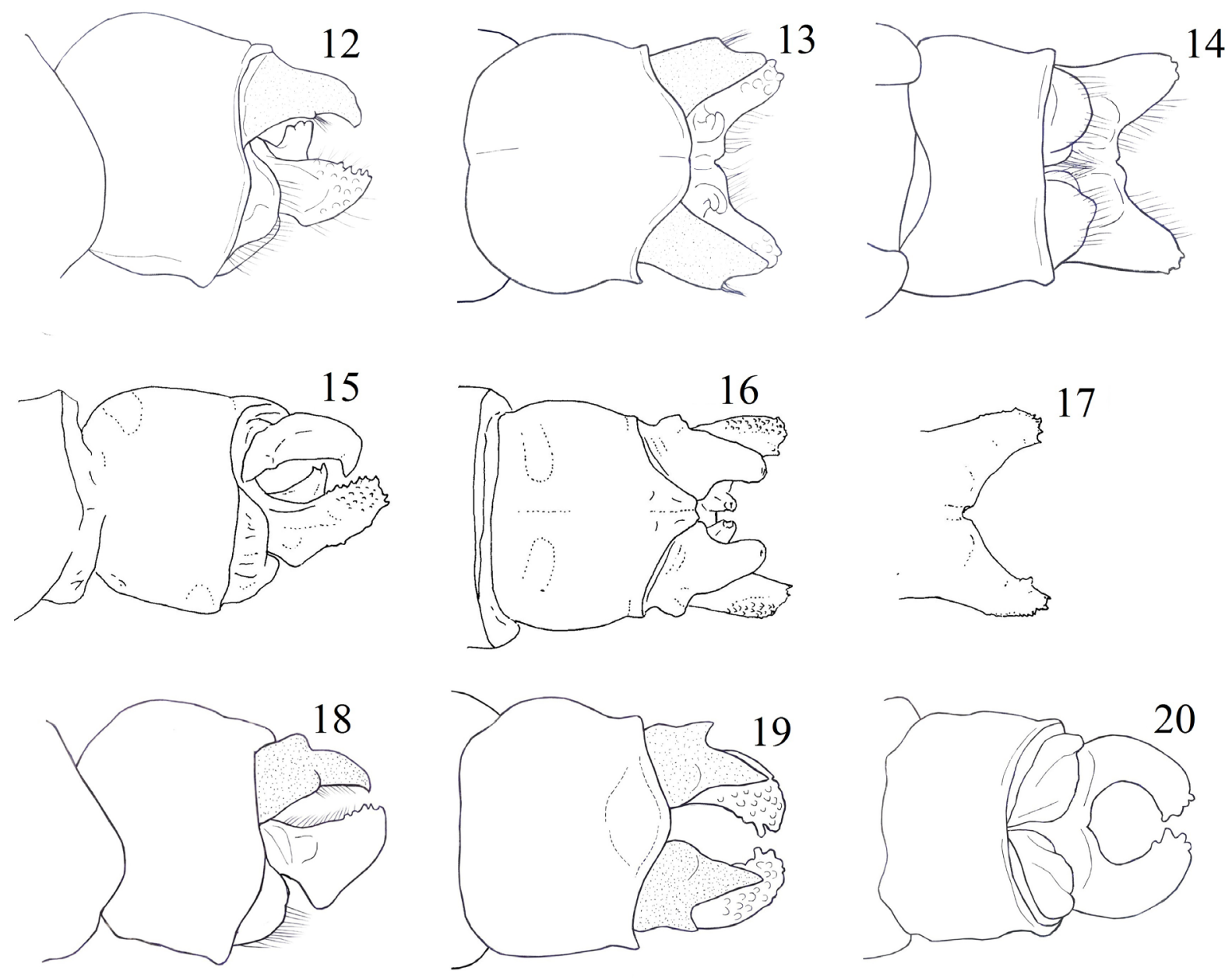

Figs 12-20. Anal appendages of species of Chlorogomphus Selys, 1854, đૅ $\widehat{~}$. 12-14. C. hoaian sp. nov., holotype (ZCDTU 2019042003-ODO). 15-17. C. fraseri St. Quentin, 1936 (KPMNH Khasi01-ODO). 18-21. C. aritai Karube, 2013 (ZCDTU 2017061901-ODO). 12, 15, 18. Anal appendages in lateral view. 13, 16, 19. Anal appendages in dorsal view. 14, 17, 20. Epiproct in ventral view. Images not to scale. 
HEAD. As in holotype male, but yellow stripe on postfrons slightly narrower (Figs 5-6) and vertex broadly spherical, with a longitudinal raised area terminating posteriorly as an expanded, club-like prominence (Fig. 25). Distance between eyes $1.5 \mathrm{~mm}$.

ThORAX AND LEGS. As in holotype male (Fig. 2).

WINGS. Hyaline with black venation. Wing colour pattern tinged with dark golden yellow and patterned as follows: on Fw, brownish band covers space between subcosta to MA vein, runs from base to just beyond nodus, extends from this point, reaching to cubital vein. Wing tip slightly brownish. Hw with a broad, arcuate brown band encompassing most of antenodals (but anterior half of antenodals hyaline), extending posteriorly to wing margin and expanding posteromedially beyond level of triangle, surrounding a large, oval hyaline patch basally. Area between brown band and small darkened mark at wing tip tinged with yellow (Figs 2, 21). Ax/Px ratio 33/17 in Fw and 24/21 in Hw. Median space with
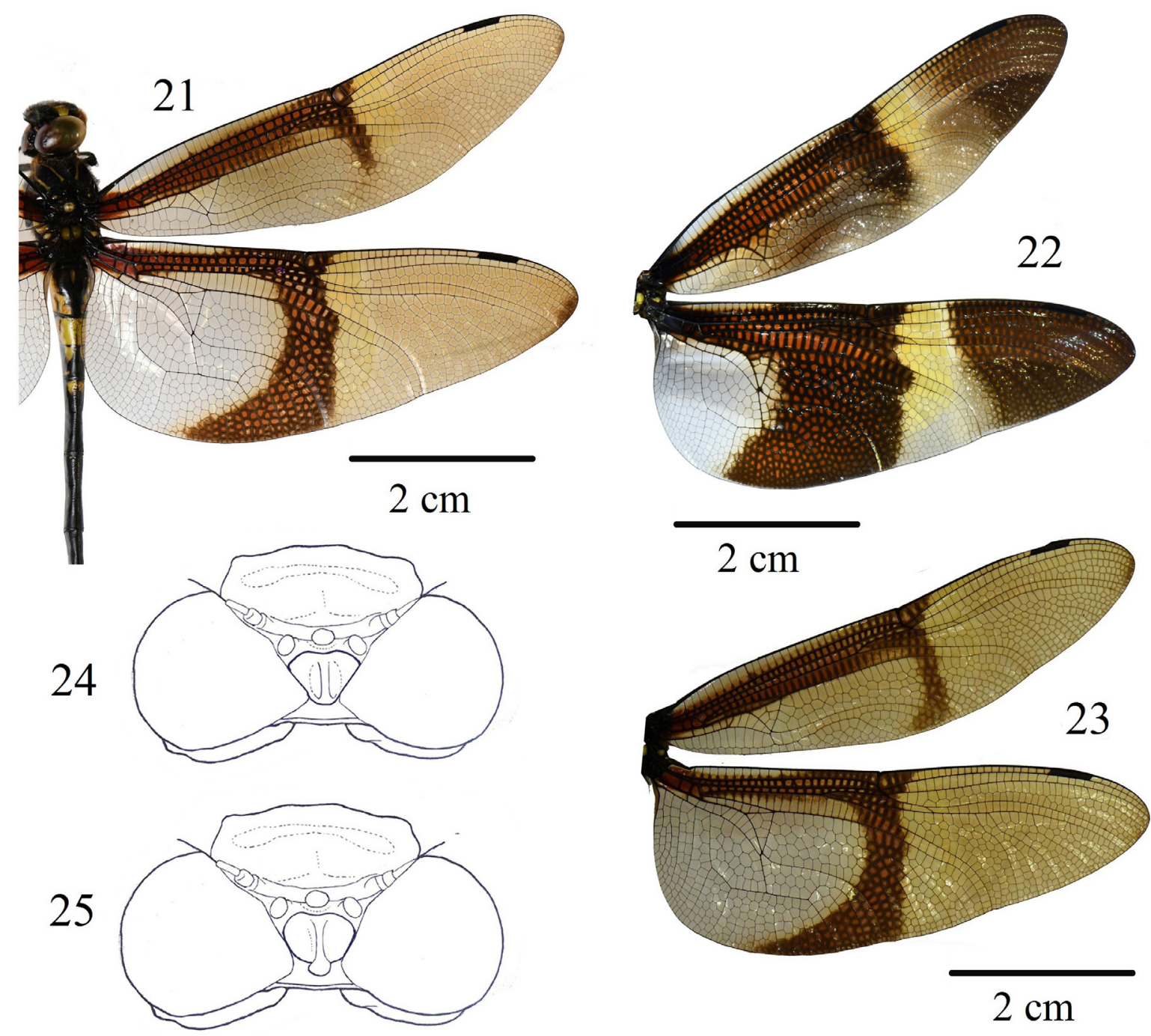

Figs 21-25. 21-23. Right wings of species of Chlorogomphus Selys, 1854, 우. 21. C. hoaian sp. nov. (ZCDTU 2019042003-ODO). 22. C. aritai Karube, 2013 (ZCDTU 2021061901). 23. C. caloptera Karube, 2013 (ZCDTU 2016042201-ODO). 24. Head of C. hoaian sp. nov., holotype, ô (ZCDTU 2019042001-ODO). 25. Head of C. hoaian sp. nov., paratype, ㅇ (ZCDTU 2019042003-ODO). $24-25$ not to scale. 
2 crossveins on all wings. Triangles 4-celled in Fw and 5-celled in Hw. Basal side of triangles of Hw longer than costal side. Cubital space with 10-11 cells in all wings. Anal loop with 26 cells. Pterostigma black, $4.2-4.5 \mathrm{~mm}$ long on all wings, covering 3.5-4 underlying cells.

ABDomen. Abdominal pattern as in holotype male, but yellow pattern slightly more extensive. S4-5 mostly black with a yellow spot at anterior margin. Yellow spot on S5 small. S6-10 entirely black (Fig. 2).

CERCI. Entirely black, narrow. Length $1 / 3$ that of S10 (Fig. 10). Valvula valvae trapezoidal-shaped, as shown in Fig. 11. Ventral projection of S10 reaches slightly beyond equal cerci (Fig. 10).

\section{Morphological variation in paratypes}

Measurement VARiation. Males: Hw 52-53 mm long, abdomen (including anal appendages) $52-56 \mathrm{~mm}$ long. Females: Hw 57-58 mm long, abdomen (including appendages) $55-58 \mathrm{~mm}$ long.

Wing venation. Males: Ax/Px ratio 26-29/14-16 in Fw and 19-23/16-17 in Hw. Cubital space with 8-9 crossveins in all wings. Anal loop 15-17-celled. Females: Ax/Px ratio 31-33/17-18 in Fw and $22-25 / 21$ in Hw. Triangles of all wings 4-5-celled. Cubital space with 10-11 cells in all wings. Anal loop with $25-26$ cells.

OTHER CHARACTERS. The S4 in a male from Ngoc Linh Nature Reserve has a tiny yellow spot at the anterior end (entirely black in the holotype and other male specimens). The width of the brown band on $\mathrm{Hw}$ of the female specimens from Ngoc Linh (ZCDTU 2019060701-ODO and 0702-ODO) and Dak Trum (ZCDTU 2018052401-ODO) are much narrower than in specimens from the type locality.

\section{Distribution}

Vietnam (Fig. 61: yellow circle): Kon Tum Province (Dak Glei District) and Gia Lai Province (Mang Yang District and Ka Bang District).

\section{Habitat and ecology}

The new species was discovered coursing up and down over small streams (2-4 m width) interspersed with large stones within dense vegetation in a pristine forest. No other specimens of Chlorogomphus were found at the type locality.

Chlorogomphus vani sp. nov. urn:1sid:zoobank.org:act:9C02830B-F58F-4024-A1E3-C7BE8DCCC11B

Figs $26-38,43,45-46,62$

\section{Diagnosis}

Within this genus, the new species seems to be closest to Chlorogomphus auratus and C. canhvang based on the similar male appendage morphology and the amber pattern on the female wings. Chlorogomphus vani sp. nov. differs from two above mentioned species by the following characters: In the male anal appendage morphology, (1) in lateral view, the cercus is shorter than the epiproct (Fig. 37), while it is subequal in C. auratus (Fig. 39) and C. canhvang (Fig. 41); (2) in dorsal view, the cercus is simple and bluntly acute apically (Fig. 38), while it is expanded apically in C. auratus (Fig. 40) and C. canhvang (Fig. 42); (3) in lateral view, S10 has no protrusion between the cerci in C. vani sp. nov. (Fig. 37), but this structure is clearly visible and stout in C. auratus (Fig. 39); and (4) the secondary genitalia of C. vani sp. nov. are similar to those in C. auratus (Karube 1995: fig. 8) but its anterior lamina is subequal in length to the posterior hamule (Fig. 32), while in C. canhvang, the anterior lamina is half the length of 
the posterior hamule (Kompier \& Karube 2018: fig. 3c). In the female, (1) the tinted golden area is less extensive and lacks the black wing tips (Fig. 43), while these features are obvious in C. canhvang and C. auratus (Fig. 44); (2) the shape of the female vertex is posterodorsally concave in C. vani sp. nov. and C. canhvang (Fig. 46), but the posterodorsal margin of the vertex of C. auratus is rounded (Kompier \& Karube 2018: fig. 3a); (3) in the synthoracic pattern, C. vani sp. nov. has five narrow yellowish stripes (Fig. 27), but C. auratus and C. canhvang only have three stripes (Kompier \& Karube 2018: fig. 1b, e); and (4) the yellow marking on the abdomen of C. vani sp. nov. (Fig. 43) is less extensive than in C. auratus or C. canhvang (Kompier \& Karube 2018: fig. 1c, f).

Female specimens of Chlorogomphus auripennis Zhang \& Cai, 2014 from southern China also have golden wings, but with a different pattern (Zhang \& Cai 2014: figs 2-3). The male of this species is easily distinguished from that of $C$. auratus, $C$. canhvang or $C$. vani sp. nov. by its cercus having a stout ventral spine at the basal $2 / 3$, thus being forked in dorsal view (Zhang \& Cai 2014: figs 6-7).

The anal appendages of Chlorogomphus shanicus Wilson, 2002 are somewhat similar to those of C. vani sp. nov., but the epiproct is relatively longer than the cerci and deeply incised in dorsal view (Wilson 2002: figs 12-13).

\section{Etymology}

'Vani', a noun in the genitive case, is named after Mr Dang Ngoc Van (born 1987), resident of Bao Loc District of Lam Dong Province, who kindly supplied the authors with the specimens of this new species, as well as other material from southern Vietnam.

\section{Material examined}

\section{Holotype}

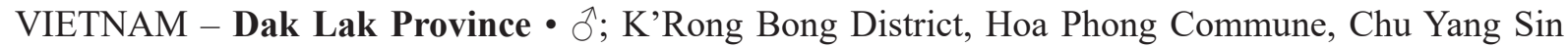
National Park; $12.4780^{\circ}$ N, $108.4617^{\circ}$ E; alt. 749 m; 20 Apr. 2021; Dang Ngoc Van leg.; ZCDTU 2021042001-ODO.

\section{Paratypes}

VIETNAM - Dak Lak Province • 1 o , 4 $\circ$ $\odot$; same collection data as for holotype; ZCDTU 2021042002ODO to 2006-ODO.

\section{Description}

Male (Figs 26, 28-29, 32-34, 37-38, 45)

MeASuREMENTs. Hw $44 \mathrm{~mm}$ long, abdomen (including appendages) $56 \mathrm{~mm}$ long.

HEAD. Labrum black with a semicircular yellowish marking at central dorsal margin. Anteclypeus black with a narrow, transverse, dark yellow stripe bordering upper margin. Postclypeus yellow with two tiny black spots mediolaterally. Antefrons prominent medially and entirely black. Postfrons black, with a narrow, transverse, yellowish cross stripe. Antennae black, but anterior part of first and second segments dark yellowish (Figs 28-29). Vertex black, hemispherical, posterior margin narrowly concave (Fig. 45). Occiput triangular, black, with long setae on posterior margin. Distance between eyes $0.3 \mathrm{~mm}$.

THORAX. Anterior and middle lobes of prothorax black, posterior lobe black with yellow marks medially. Synthorax black with three yellowish stripe markings as follows: dorsal stripe on mesepisternum narrow; lateral stripes on mesepisternum and metepisternum well developed and broader than dorsal ones; mesepimeron entirely black; metinfraepisternum black with large yellow marking. Coxae and trochanter of fore legs largely yellowish, remainder black; middle and hind legs entirely black (Fig. 26). 
WINGs. Hyaline with black venation (Fig. 26). Ax/Px ratio 21/14 in Fw and 19/14 in Hw. In all wings, median space with 1 crossvein. In Hw, basal triangle with 3 cells. Triangle 4-celled and 3-celled in Fw and $\mathrm{Hw}$, respectively, with costal side equal to basal side. Cubital space with 7 crossveins in Fw and

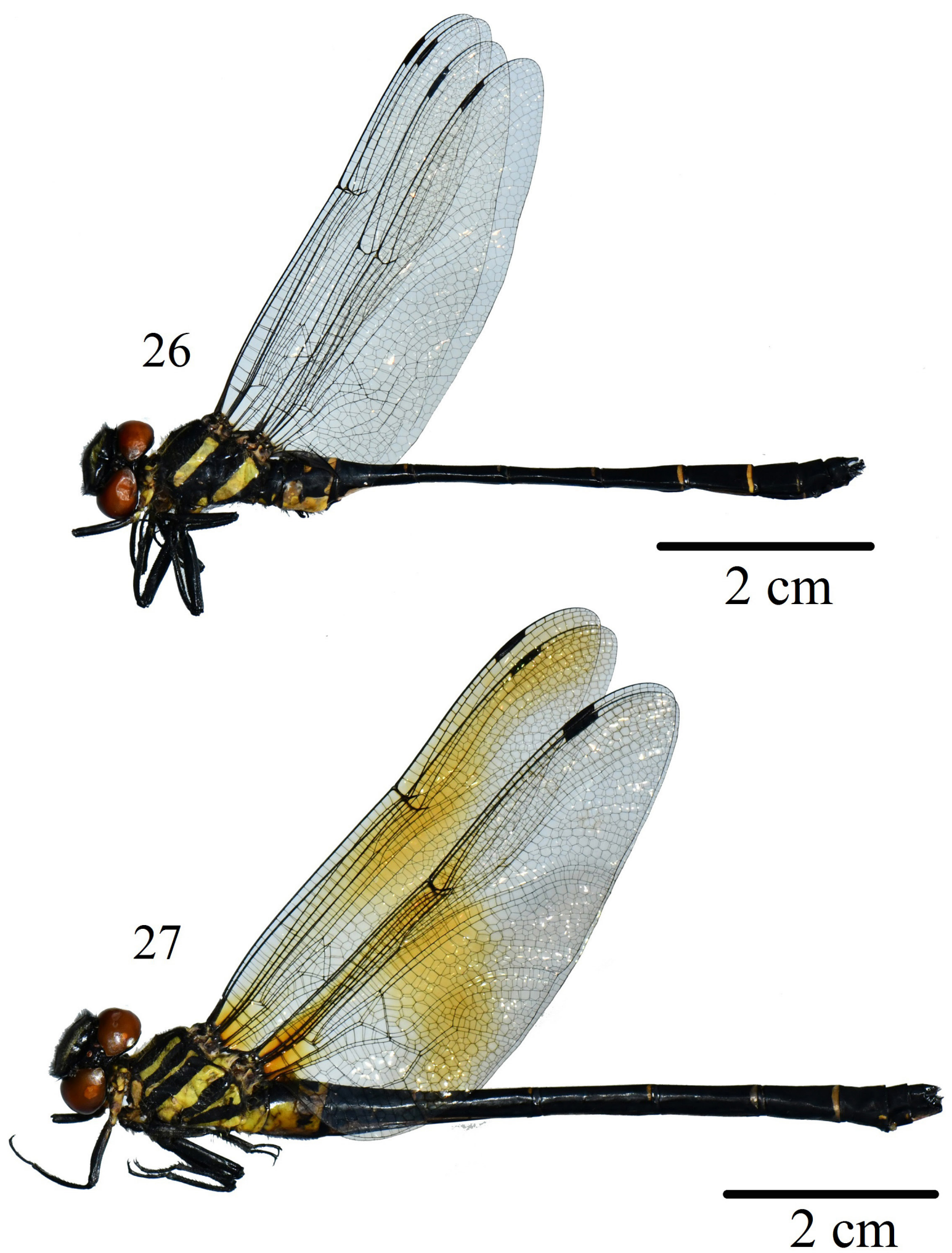

Figs 26-27. Habitus of Chlorogomphus vani sp. nov. 26. Holotype, § (ZCDTU 2021042001-ODO). 27. Paratype, $q$ (ZCDTU 2021042003-ODO). 
8 crossveins in Hw. Anal loop 14-celled. Pt black, 3-3.2 mm long on both wings, covering 3.5 underlying cells.

AвDOMEN. S1 black with two small yellow spots latero-ventrally. S2 black, dorsally with a yellow spot, distal margin yellowish with another larger yellow marking covering half latero-ventrally. S1-2 broad, subsequently narrower toward tip from S3; S3 with a small yellow anteroventral spot; S3-5 with a small yellow ventral spot; S6-7 black, each with a subapical dorsal spot; S8 black with a short yellow lateroventral strip; S9 entirely black; S10 black with a yellowish marking on ventral side (Fig. 26).

SECONDARY GENITALIA. Anterior lamina broad basally, gradually narrowing apically and strongly curved posteriorly. Posterior hamule thin, as long as anterior lamina, slightly curved anteriorly at tip (Fig. 32).

Vesica SPERMALIS. With typical shape in the genus, as in Figs 33-34. Terminal segment with two long projections and dorsal part of terminal segment subequal to ventral plate; second segment broader and with a stout spine.

AnAl APPENDAGes. Black. Cercus as long as S10, with a simple structure. In lateral and dorsal view, cercus broad basally, gradually narrowing apically; tip rounded, slightly curved ventrally in lateral view
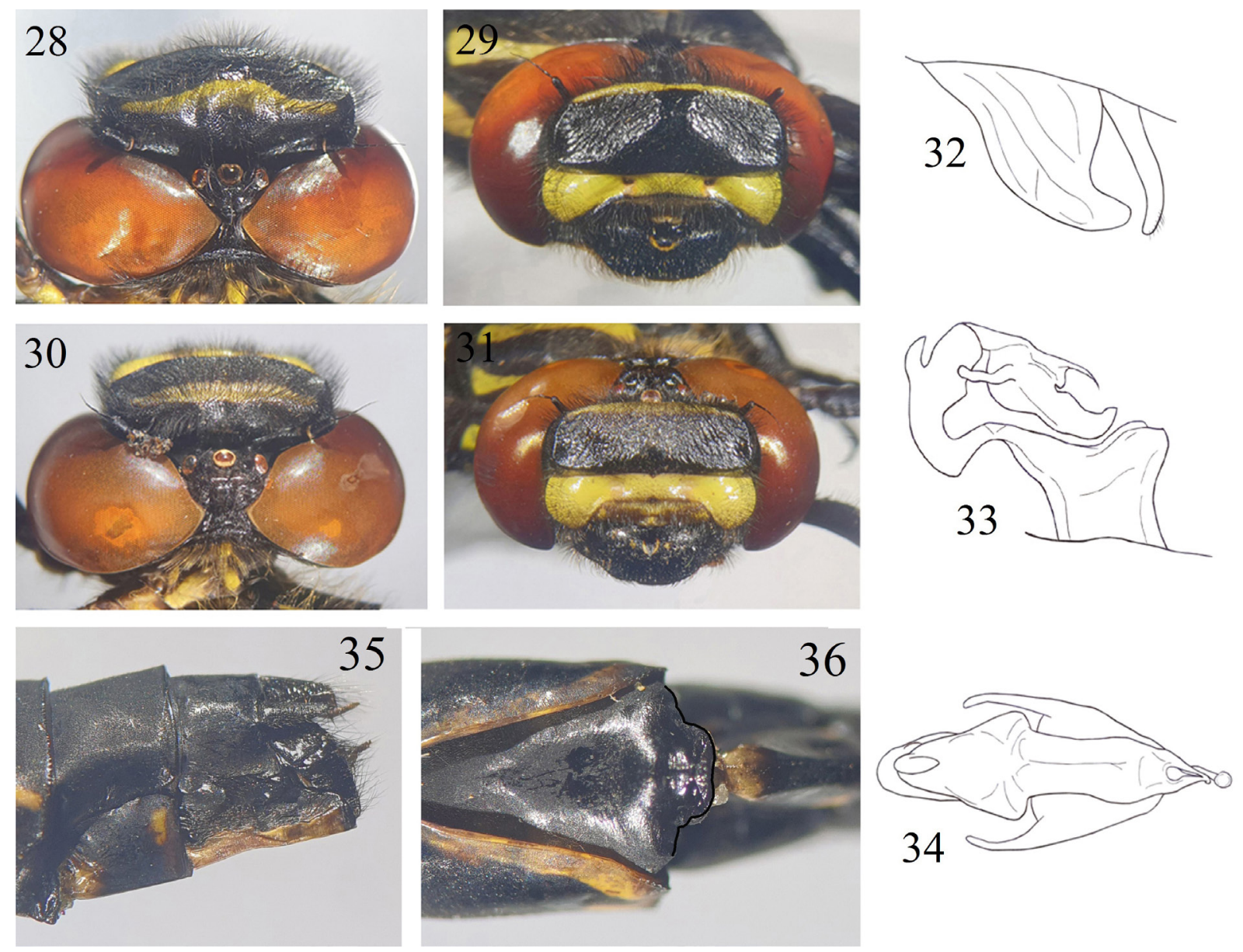

Figs 28-36. Features of Chlorogomphus vani sp. nov., holotype, ô (28-29, 32-34) (ZCDTU 2021042001ODO) and paratype, $q$ (30-31, 35-36) (ZCDTU 2021042003-ODO). 28-29. Head in dorsal and frontal views. 30-31. Head in dorsal and frontal views. 32. Accessory genitalia. 33. Vesica spermalis in lateral view. 34. Terminal segment of vesica spermalis in ventral view. 35-36. Abdominal tip in lateral and ventral views. Images not to scale. 
(Figs 37-38). Epiproct in lateral view longer than cercus, abruptly curved dorsally at apical fourth and armed apically with two short teeth (Fig. 37) in dorsal view, epiproct broadly concave apically (Fig. 38).

Female (Figs 27, 30-31, 35-36, 43, 46)

MeASUREMENTS. Hw $53 \mathrm{~mm}$ long, abdomen (including appendages) $63 \mathrm{~mm}$ long.

HEAD. As in holotype male, but anteclypeus of head dark yellowish with brownish marking ventrally; postfrons with a dorsal transverse yellow stripe, curved medially as in holotype male (Figs 30-31); circular vertex larger than in male, its posterior margin concave, V-shaped (Fig. 46). Distance between eyes $1.4 \mathrm{~mm}$.
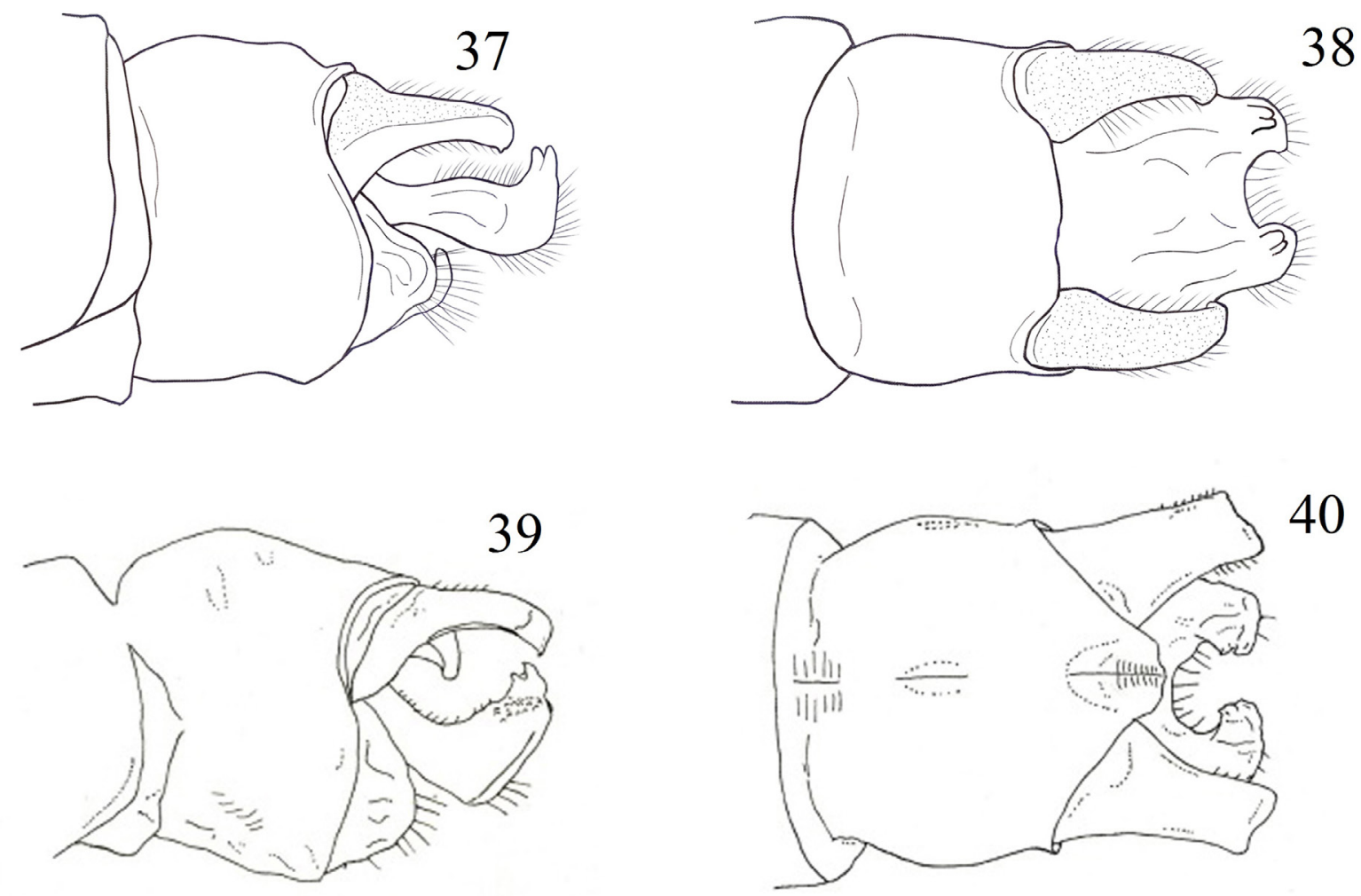

40
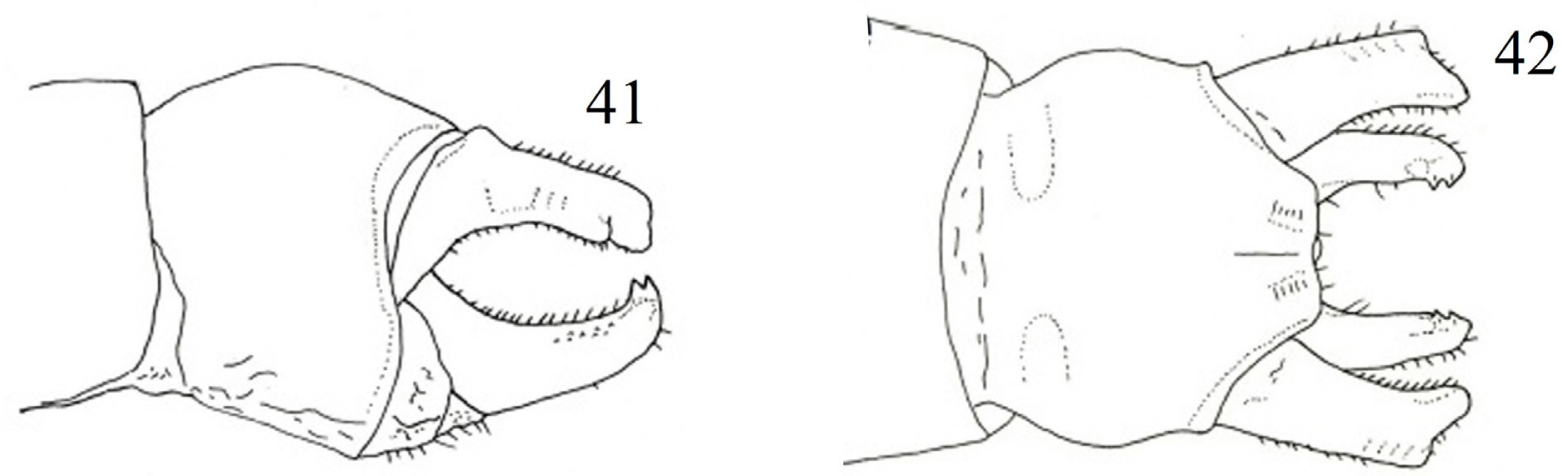

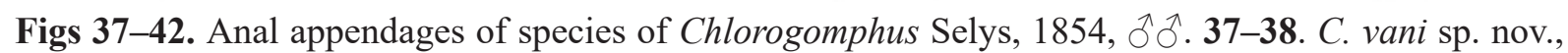
holotype (ZCDTU 2021042001-ODO). 39-40. C. auratus Martin, 1910 (rearranged from Kompier \& Karube 2018: fig. 2a-b). 41-42. C. canhvang Kompier \& Karube, 2018 (rearranged from Kompier \& Karube 2018: fig. 2e-f). 37, 39, 41. Anal appendages in lateral view. 38, 40, 42. Anal appendages in dorsal view. Images not to scale. 
Thorax AND Legs. Prothorax and legs as in holotype male. Synthorax black with several yellowish areas as follows: dorsal stripe on mesepisternum narrow; lateral stripe on mesepisternum broader, slightly sinuous; stripes on mesepimeron slender, longer than those on mesepisternum; lateral stripe on metepisternum largest, covering most of segment and overlapping spiracle and part of metinfraepisternum; mesepimeron black with dorsal and ventral margin yellowish, upper stripe narrow anteriorly, broader near wing base, inner alar sclerite yellow (Fig. 27).

WINGS. Hyaline with amber pattern as follows: on Fw, amber pattern interrupted, beginning to extend from about $15^{\text {th }}$ Ax to wingtip, darker around nodus; on $\mathrm{Hw}$ amber pattern runs from base, covering Ax and beginning to extend from about $14^{\text {th }}$ Ax to just beyond nodus and to distal margin of anal loop (Figs 27, 43). Ax/Px ratio 25/13 and 20/18 in Fw and Hw, respectively. In all wings, median space with 2 crossveins. Triangles with 4 cells in all wings. Triangle in $\mathrm{Hw}$ with costal side equal to basal side. Cubital space with $9-10$ crossveins in all wings. Anal loop 19-celled. Pt black, 4 mm long on all wings, surmounting 3.5 underlying cells.

ABDomen. Black, with yellowish markings as follows: half ventral of S1 (Fig. 27); S2 except for anterodorsally black; S3-7 with a small yellow anteroventral spot, each subsequently becoming larger on successive segments; S8-9 with a small anteroventral yellow spot; S10 entirely black (Fig. 27).

CERCI. Black, as long as S10 (Fig. 35). Valvula valvae trapezoid-shaped, as in Fig. 36. Ventral projection of $\mathrm{S} 10$ reaches beyond equal cerci (Fig. 35).
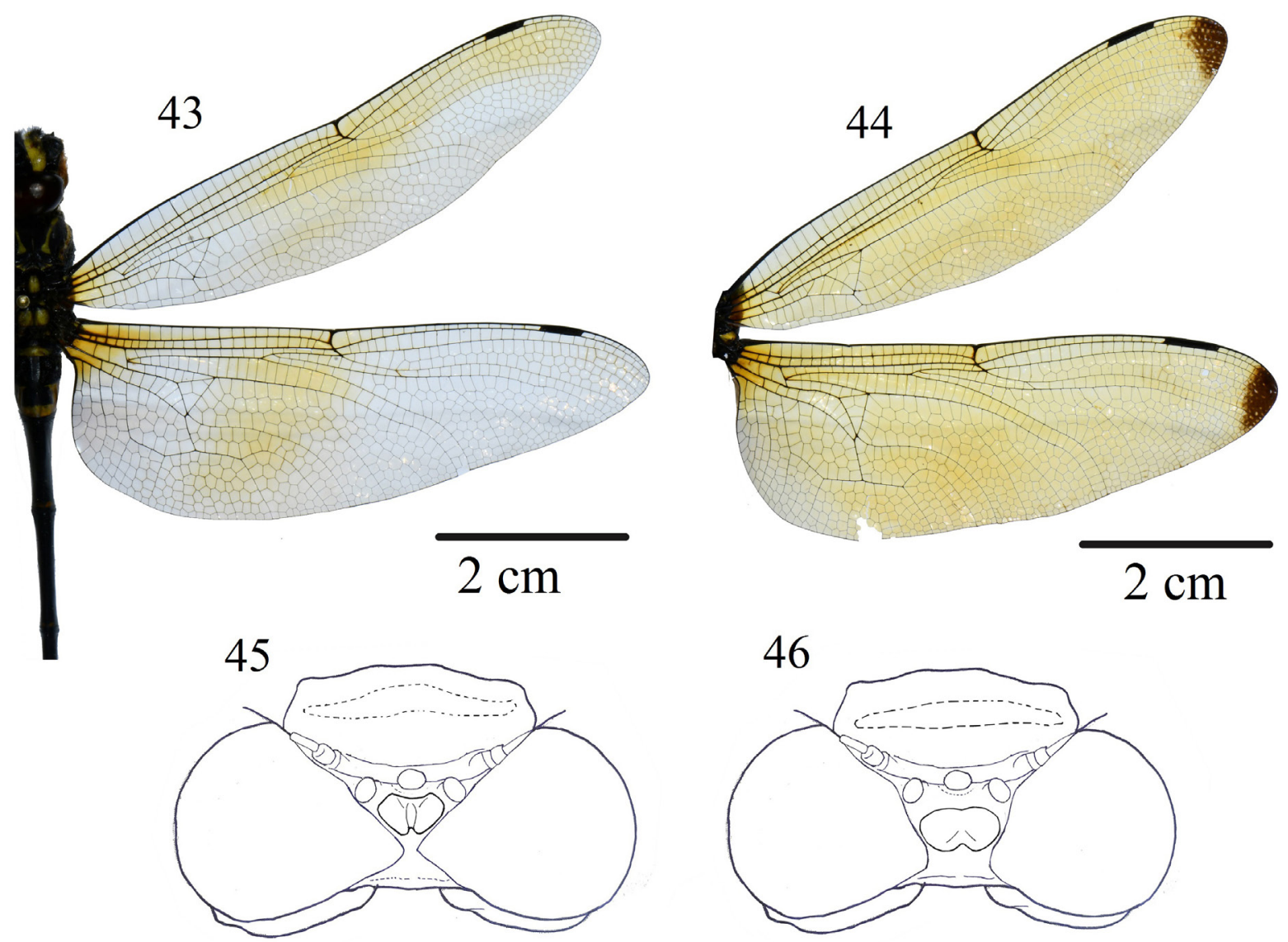

Figs 43-46. 43-44. Right wings of species of Chlorogomphus Selys, 1854, q + . 43. C. vani sp. nov., paratype (ZCDTU 2021042003-ODO). 44. C. auratus Martin, 1910 (ZCDTU 2020060905-ODO). 45. Head of C. vani sp. nov., holotype, ô (ZCDTU 2021042001-ODO). 46. Head of C. vani sp. nov., paratype, $q$ (ZCDTU 2021042003-ODO). 45-46 not to scale. 


\section{Morphological variation in paratypes}

Measurement variation. Male: abdomen (including appendages) $58 \mathrm{~mm}$ long. Females: Hw 52-53 mm long, abdomen (including appendages) 60-65 mm long.

Wing venation. Male: Ax/Px ratio 22/11 and 17/15 in Fw and Hw, respectively. Triangle 3-celled in all wings. Cubital space with 6 cells in Hw. Females: Ax/Px ratio 24-26/12-14 and 19-21/16-19 in Fw and $\mathrm{Hw}$, respectively. Median space with $2-3$ crossveins in all wings. Cubital space with 9-10 crossveins in all wings. Anal loop 16-17-celled.

OTHER CHARACTERS. Male paratype differs from holotype by having yellow marking on S8 extending posteriorly to latero-ventral margin. One paratype female darker golden than the others, with the tip of Hw slightly amber.

\section{Distribution}

Vietnam (Fig. 62: yellow rectangle): Dak Lak (Chu Yang Sin National Park) Province.

Chlorogomphus gracilis Wilson \& Reels, 2001

Figs 47-60, 63

\section{Material examined}

VIETNAM - Kon Tum Province $\bullet 2$ $\widehat{\jmath}$; Dak Glei District, Ngoc Linh Commune, Ngoc Linh Nature Reserve; $15.0444^{\circ} \mathrm{N}, 107.9270^{\circ} \mathrm{E}$; alt. 1480 m; 5 Jun. 2019; Q.T. Phan leg.; ZCDTU 2019060501-ODO

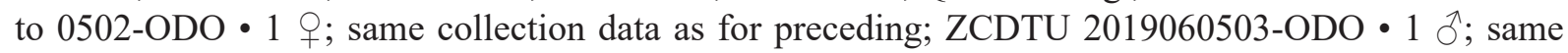
locality as for preceding; 12 May 2017; Dang Ngoc Van leg.; KPMNH 2017051201.

\section{Remarks}

Chlorogomphus gracilis is a new record for the Vietnamese fauna and for continental Asia. The body coloration and all structural features of the Vietnamese specimens (Figs 47-60) agree well with the original description of C. gracilis from Hainan. There is only one exception, i.e., that the epiproct of the Vietnamese specimens is gently expanded apically (Fig. 58), whereas in the Chinese C. gracilis it is narrower from its base to the tip (Wilson \& Reels 2001: fig. 77; Zhang 2019: 530). Wilson \& Reels (2001) considered $C$. gracilis as similar to $C$. fraseri by the similarity of having a peg-like process in the epiproct, but the illustrated epiproct from the holotype has only a single process arising from the center. Wilson \& Reels (2001) described the "hooked peg-like process arising from the centre of the base plate formed by the two conjoined inferior appendages". This process on the epiproct of the holotype of C. gracilis (Wilson \& Reels 2001: fig. 77) differs from conditions in the Vietnamese specimens, which have two long erect spines rising from the base of the epiproct (Figs 58-59) that are not conjoined. Zhang (2019: 530) also provided two photos of the anal appendages of $C$. gracilis from Hainan, but the structure of the process arising from the basal epiproct is not clearly visible in lateral and dorsal views. We consider that the single peg-like process, albeit formed from conjoined pegs, described and figured in Wilson \& Reels (2001: fig. 78) is an extraordinary character within the genus (with several other species of Chlorogomphus having two separate spines arising from the base of the epiproct; see, e.g., Fig. 13 for $C$. hoaian sp. nov. and Fig. 16 for $C$. fraseri). We cannot verify differences in other characters such as secondary genitalia and the vesica spermalis between specimens of $C$. gracilis from Vietnam and Hainan, since Wilson \& Reels (2001) did not provide sufficiently detailed drawings of these structures in their original description. Keith Wilson kindly supplied us with detailed images of the head and the abdominal tip of female $C$. gracilis from Hainan. The shape of the vertex and valvula valvae of the Hainan specimen appear to be identical to conditions in our Vietnamese female (Figs 51, 57). 


\section{Habitat and ecology}

Chlorogomphus gracilis was observed only at a small rocky stream on a high mountain (altitude nearly $1500 \mathrm{~m}$ ) near a main road. We conducted surveys at other streams at elevations of 1000-2000 m along the same road but did not find any other individuals of this species or any other Chlorogomphidae.

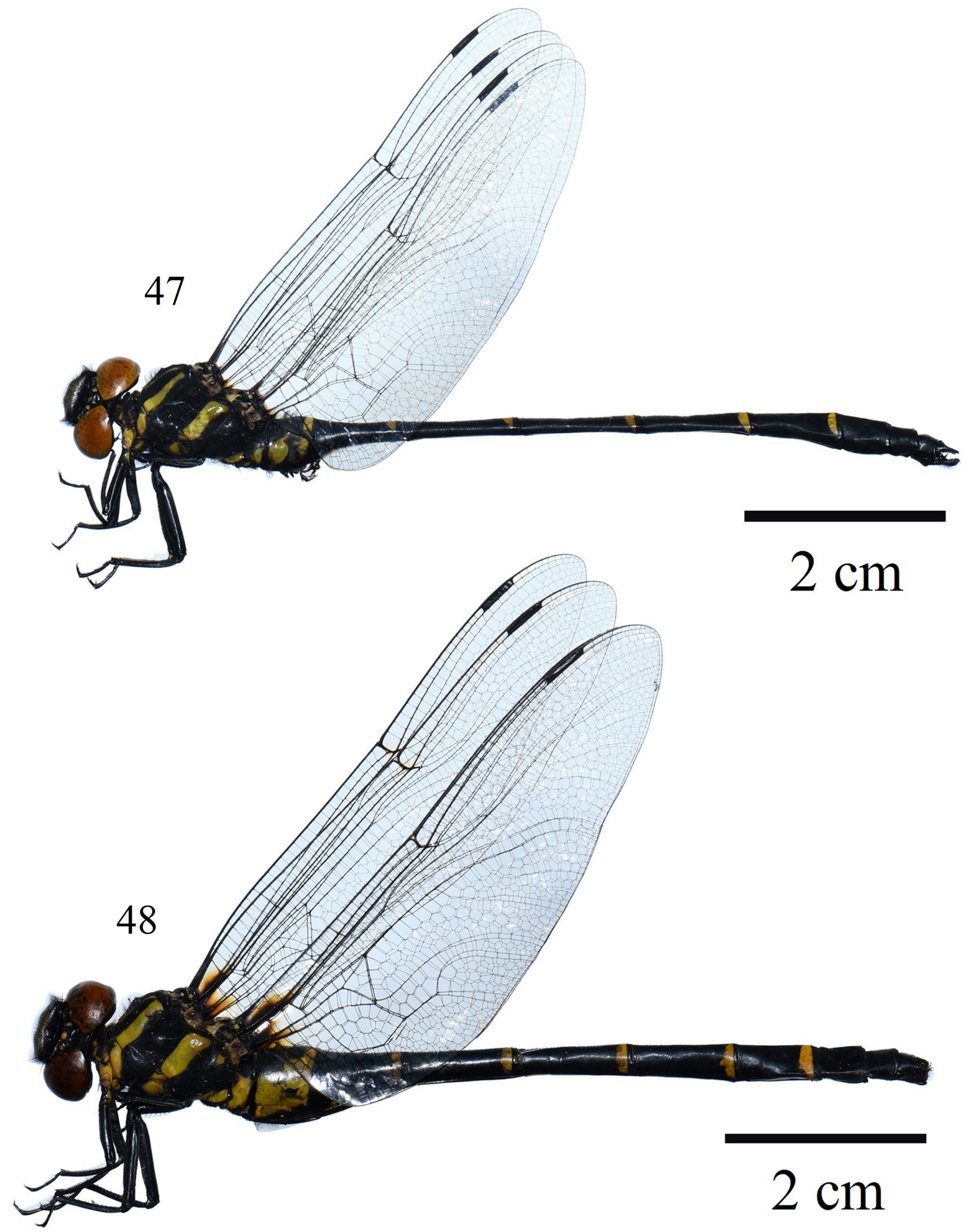

Figs 47-48. Habitus of Chlorogomphus gracilis Wilson \& Reels, 2001. 47. $\widehat{~}$ (ZCDTU 2019060501ODO). 48. ㅇ (ZCDTU 2019060503-ODO). 


\section{Distribution}

Vietnam: Kon Tum (Ngoc Linh Nature Reserve) Province; China: Hainan Island (Fig. 63: red triangle).

\section{Discussion}

Within the family Chlorogomphidae, two species, Chlorogomphus montanus Chao, 1999 (from Hubei, Fujian and Guangdong, China) and C. schmidti Asahina, 1986 (from Manipur State, India), are known only based on females (Asahina 1986; Chao 1999). As pointed out by Karube (2013), describing new species based only on female specimens should be avoided, because they resemble one another in color pattern and in the structure of anal appendages and valvula, although the females of some species have characteristic wing patterns. Chlorogomphus hoaian sp. nov. and C. vani sp. nov. have golden-tinted or amber wings, while they are completely hyaline in $C$. schmidti; the wings of $C$. montanus are almost hyaline with basal brown markings in the Hw (Zhang 2019: 541). Females of C. montanus have a long abdomen $(67-75 \mathrm{~mm})$ and long $\mathrm{Hw}(60 \mathrm{~mm})$ compared with $60-63 \mathrm{~mm}$ and $53-56 \mathrm{~mm}$, respectively, in C. hoaian sp. nov. and C. vani sp. nov. The valvula valvae of C. vani sp. nov. is trapezoid-shaped (Fig. 57), as in C. schmidti (Asahina 1986: fig. 47), but pyramid-shaped in C. montanus (Chao 1999: fig. 5). In addition, C. schmidti from India is also geographically separated from C. hoaian sp. nov. and C. vani sp. nov. in Vietnam. Based on these observations, we consider it safe to describe the two new species from the Central Highlands of Vietnam here.
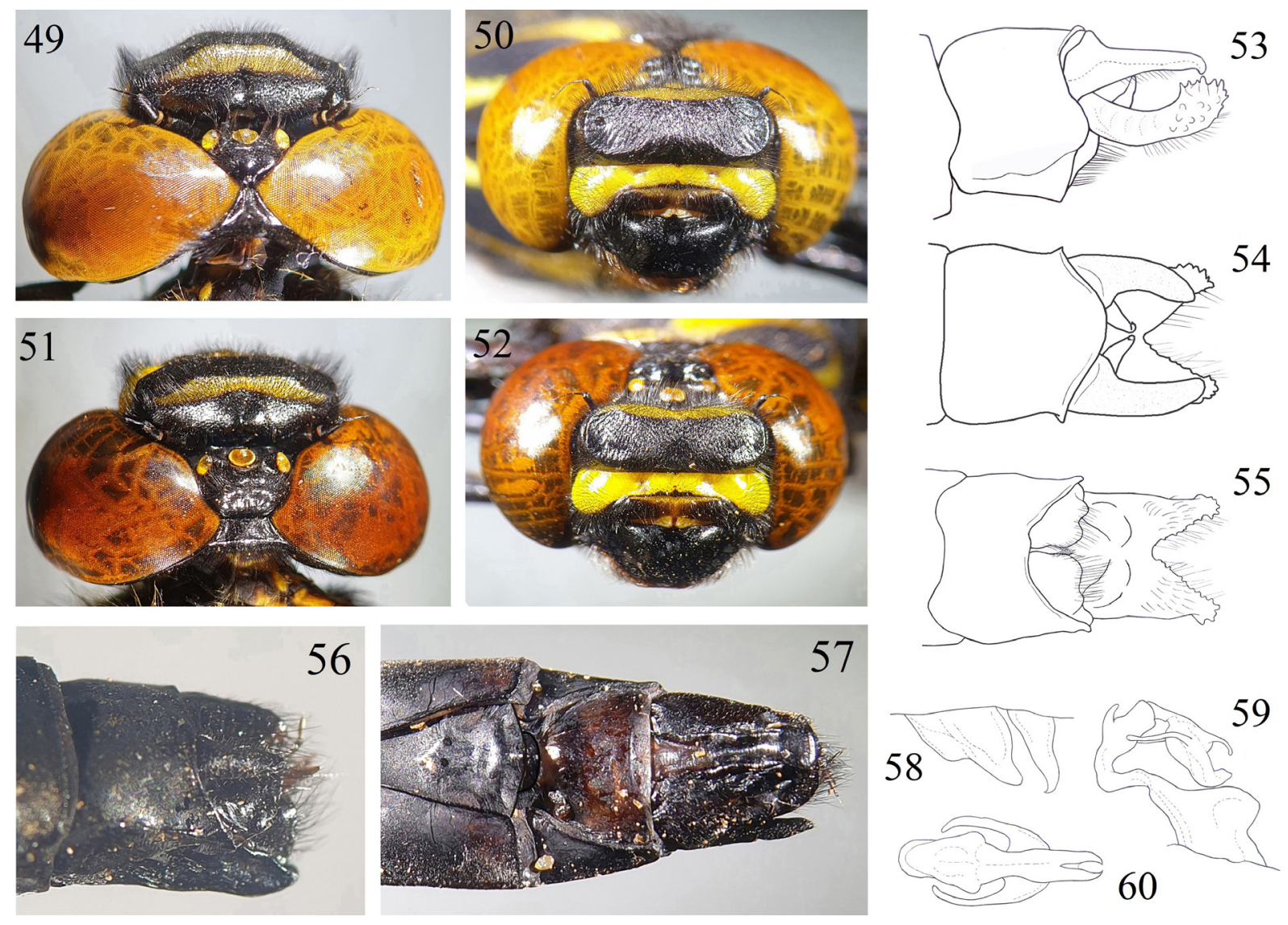

Figs 49-60. Features of Chlorogomphus gracilis Wilson \& Reels, 2001, ठิ (49-50, 53-55, 58-60) (ZCDTU 2019060501-ODO) and + (51-52, 56-57) (ZCDTU 2019060503-ODO). 49-50. Head in dorsal and frontal views. 51-52. Head in dorsal and frontal views. 53-55. Anal appendages in lateral, dorsal and ventral views. 56-57. Abdominal tip in lateral and ventral views. 58. Accessory genitalia. 59. Vesica spermalis in lateral view. 60. Terminal segment of vesica spermalis in ventral view. Images not to scale. 

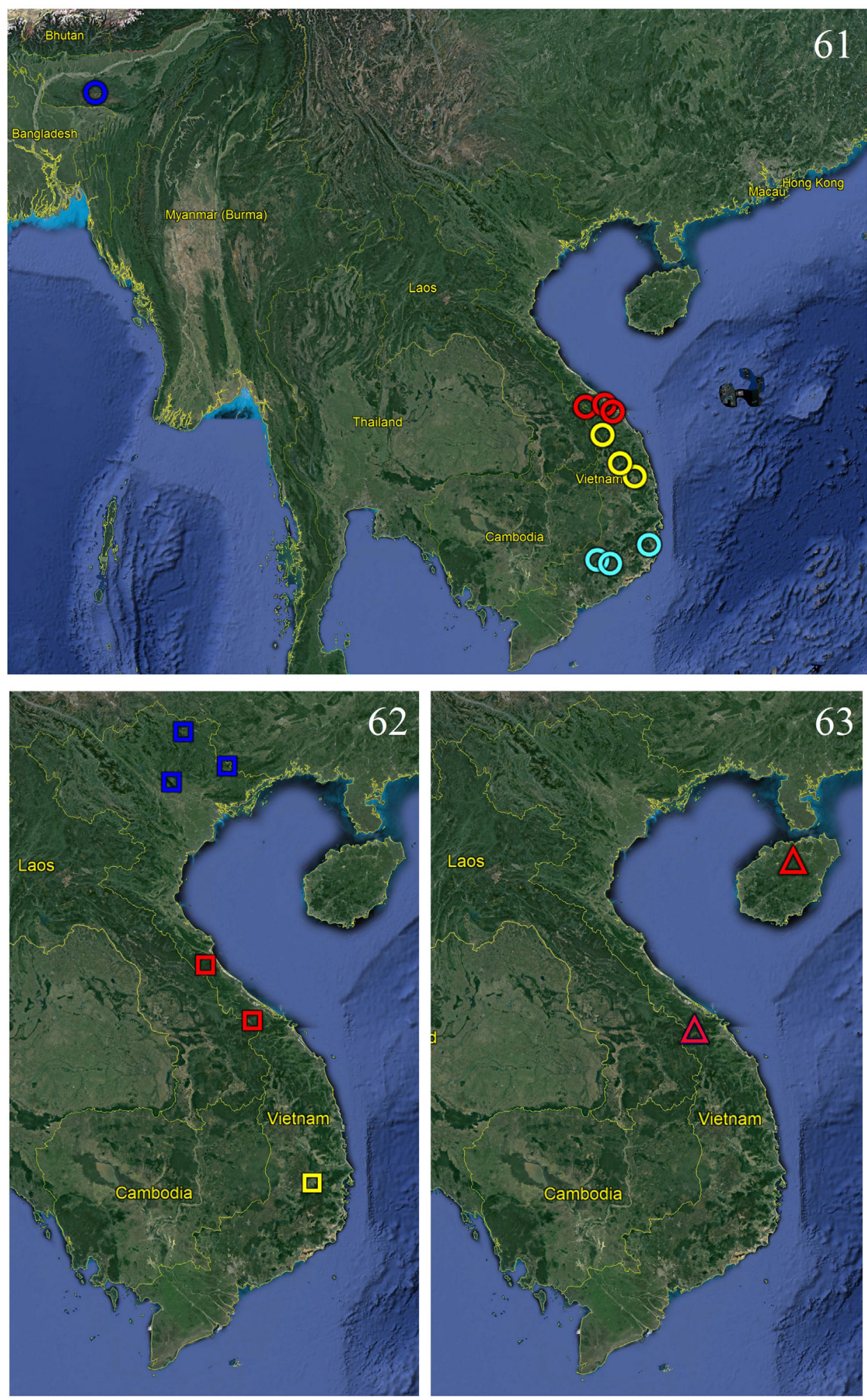

Figs 61-63. Distribution maps of species of Chlorogomphus Selys, 1854. 61. Distribution map of C. fraseri St. Quentin, 1936 (dark blue circle), C. aritai Karube, 2013 (red circles), C. hoaian sp. nov. (yellow circles) and C. caloptera Karube, 2013 (light blue circles). 62. Distribution map of C. auratus Martin, 1910 (blue squares), C. canhvang Kompier \& Karube, 2018 (red squares) and C. vani sp. nov. (yellow square). 63. Distribution map of C. gracilis Wilson \& Reels, 2001 (red triangles) in Vietnam and China. 
The two new species and their congeners have allopatric distributions in Vietnam and other countries: C. hoaian sp. nov. is thus far known only from high altitude evergreen forests in the Central Highlands, but $C$. aritai is found only around Da Nang City and in Thua Thien Hue Province in central Vietnam, C. caloptera is from southern Vietnam, and C. fraseri is known from India (Fig. 61). Chlorogomphus auratus was found in northern Vietnam, C. canhvang in north-central Vietnam, and both species also occur in southern China (Zhang 2019). Chlorogomphus vani sp. nov. is found in the Central Highlands (Fig. 62). However, the identification of a male of C. canhvang from southern China by Zhang (2019: 507 ) is doubtful, because the presence of a laterally clearly visible projection on the dorsal margin between the cerci is not in agreement with $C$. canhvang at all. This may be another closely related species, and study of further specimens of C. canhvang sensu Zhang (2019) from southern China is required.

\section{Acknowledgments}

We thank Mr Dang Ngoc Van for supplying the examined specimens; Dr Rosser William Garrison, Dr Rory Dow, Dr Keith Wilson, Dr Dinh Van Khuong and an anonymous referee for extensive review of the manuscript; the directorates of Kon Ka Kinh National Park, Chu Yang Sin National Park and Ngoc Linh Nature Reserve for providing support and collecting permissions; and Mr Ngo Quoc Phu (Duy Tan University) for his assistance with the field surveys. This research was funded mainly by the Vietnam National Foundation for Science and Technology Development (NAFOSTED) under grant number 106.05-2018.351.

\section{References}

Asahina S. 1969. South Vietnam Odonata taken by Mr. Y. Inoue. Japanese Journal of Zoology 16: 1-18. Asahina S. 1981. A new Chlorogomphus from Thailand (Odonata, Cordulegasteridae). Proceedings of the Japanese Society of Systematic Zoology 20: 35-38. https://doi.org/10.19004/pjssz.20.0_35

Asahina S. 1986. Revisional notes on Nepalese and Assamese dragonfly species of the genus Chlorogomphus (Odonata: Cordulegasteridae). Cho Cho 9 (1): 11-26.

Asahina S. 1995. Records of the northern Vietnamese Odonata taken by the expedition members from the National Science Museum, Tokyo. 1. Cordulegasteridae. Bulletin of the National Science Museum, Tokyo, Series A 21: 219-229.

Asahina S. 1998. Further notes on Odonata from northern Vietnam. 1. Cordulegasteridae. Bulletin of the National Science Museum, Tokyo, Series A 24 (1): 11-16.

Chao H.F. 1999. A study of Chinese dragonflies of the family Chlorogomphidae, with description of two new species and first descriptions of the male sex of a known species (Anisoptera: Chlorogomphidae). Wuyi Science Journal 15: 1-11.

Karube H. 1995. On the genus Chlorogomphus (Anisoptera: Chlorogomphidae) of Indochina with descriptions of six new species and little known species. Bulletin of Kanagawa Prefectectural Museum (Natural Sciences) 24: 47-62.

Karube H. 2001. New species of the genus Chlorogomphus from Yunnan, China (Cordulegastridae: Chlorogomphinae). Tombo, Fukui 43: 9-11.

Karube H. 2013. Survey of the Vietnamese Chlorogomphidae (Odonata), with special reference to grouping. Tombo, Fukui 55: 13-43.

Karube H. 2015. Additional records of Vietnamese Odonata I, with descriptions of two new gomphid species. Tombo, Fukui 57: 27-35. 
Karube H. \& Phan Q.T. 2016. Discovery of Chlorogomphus papilio Ris, 1927 from northern Vietnam. Tombo, Fukui 58: 49-51.

Kompier T. 2014. Dragonflies and Damselflies of Vietnam.

Available from http://odonatavietnam.blogspot.com [accessed 15 Sep. 2021].

Kompier T. \& Karube H. 2018. Chlorogomphus canhvang sp. nov. from Central Vietnam (Odonata: Chlorogomphidae). Zootaxa 4394 (3): 437-442. https://doi.org/10.11646/zootaxa.4394.3.9

Martin R. 1910. Un nouveau Chlorogomphus Selys [Nevr. Cordulegastrinae]. Bulletin de la Société entomologique de France 1910: 65-66.

Available from https://www.biodiversitylibrary.org/page/10013772 [accessed 28 Jan. 2022].

Paulson D., Schorr M. \& Deliry C. 2021. World Odonata List.

Available from http://www2.pugetsound.edu/academics/academic-resources/slater-museum/

biodiversity-resources/dragonflies/world-odonata-list2/ [accessed 1 Dec. 2021].

Phan Q.T., Karube H., Hung N.V. \& Anh T.D. 2021. Description of Chlorogomphus danhkyi sp. nov. from Vu Quang National Park, central Vietnam with notes on other congeners from the Park (Odonata: Chlorogomphidae). Zootaxa 4985 (1): 102-110. https://doi.org/10.11646/zootaxa.4985.1.6

Sasamoto A., Yokoi N. \& Teramoto T. 2011. Description of a new Sinorogomphus from Northern Laos (Odonata: Chlorogomphidae). International Journal of Odonatology 14 (1): 83-89.

https://doi.org/10.1080/13887890.2011.571982

Wilson K.D.P. 2002. Notes on Chlorogomphidae from Southern China, with descriptions of two new species (Anisoptera). Odonatologica 31 (1): 65-72.

Wilson K.D.P. \& Reels G.T. 2001. Odonata of Hainan, China. Odonatologica 30 (2): 145-208.

Zhang H.M. 2019. Dragonflies and Damselflies of China. Chongqing University Press, Chongqing.

Zhang H.M. \& Ca Q.H. 2014. Description of Chlorogomphus auripennis spec. nov. from Guangdong Province, with new records of Chlorogomphidae from Yunnan Province, China (Odonata: Chlorogomphidae). Zootaxa 3790 (3): 477-486. https://doi.org/10.11646/zootaxa.3790.3.6

Manuscript received: 23 February 2021

Manuscript accepted: 10 December 2021

Published on: 17 February 2022

Topic editor: Nesrine Akkari

Desk editor: Danny Eibye-Jacobsen

Printed versions of all papers are also deposited in the libraries of the institutes that are members of the EJT consortium: Muséum national d'histoire naturelle, Paris, France; Meise Botanic Garden, Belgium; Royal Museum for Central Africa, Tervuren, Belgium; Royal Belgian Institute of Natural Sciences, Brussels, Belgium; Natural History Museum of Denmark, Copenhagen, Denmark; Naturalis Biodiversity Center, Leiden, the Netherlands; Museo Nacional de Ciencias Naturales-CSIC, Madrid, Spain; Real Jardín Botánico de Madrid CSIC, Spain; Zoological Research Museum Alexander Koenig, Bonn, Germany; National Museum, Prague, Czech Republic. 